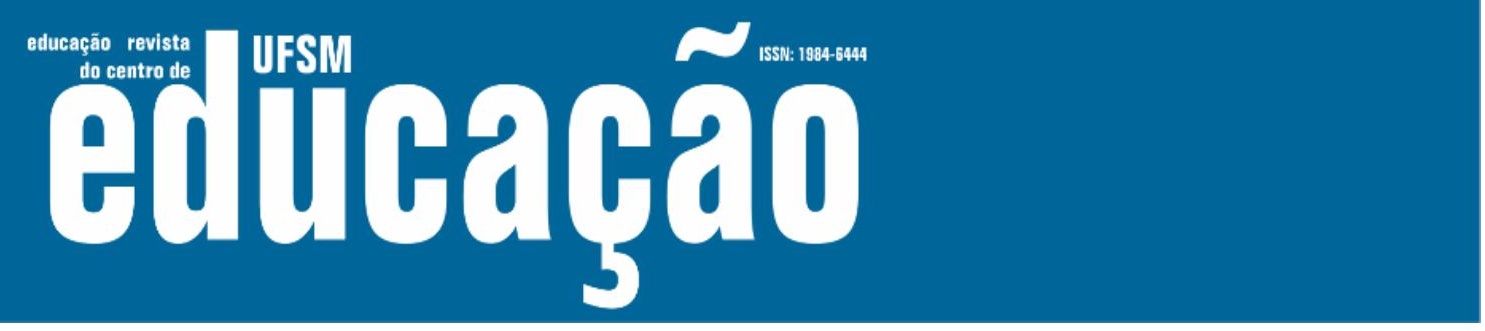

ISSN: 1984-6444 | http://dx.doi.org/10.5902/19846444447227

\title{
Condições de trabalho docente na escola da atualidade: demandas e desafios, na percepção de educadores da rede pública estadual paulista
}

Teaching work conditions at today's school: demands and challenges, according to the São Paulo's public-school educators

Vera Maria Nigro de Souza Placco

Professora doutora na Pontifícia Universidade Católica de São Paulo. São Paulo, São Paulo, Brasil. veraplacco7@gmail.com - https://orcid.org/0000-0001-9515-2370

Luciana Andréa Afonso Sigalla

Professora doutora na Pontifícia Universidade Católica de São Paulo. São Paulo, São Paulo, Brasil. luciana.sigalla@gmail.com - https://orcid.org/0000-0002-8965-9551

Simone Pannocchia Tahan

Doutoranda na Pontifícia Universidade Católica de São Paulo. São Paulo, São Paulo, Brasil. simone@parthenonplus.com - https://orcid.org/0000-0001-8433-3168

Luzia Angelina Marino Orsolon

Pontifícia Universidade Católica de São Paulo. São Paulo, São Paulo, Brasil.

luorsolon@uol.com.br - http://orcid.org/0000-0001-5057-1686

Gabriela Argolo

Professora doutora na Pontifícia Universidade Católica de São Paulo. São Paulo, São Paulo, Brasil. gabrielasargolo@gmail.com - https://orcid.org/0000-0002-6406-9432

Recebido em 13 de junho de 2020

Aprovado em 10 de setembro de 2020

Publicado em 27 de janeiro de 2022

\section{RESUMO}

Este artigo apresenta um recorte da pesquisa-mãe "Desafios da escola na atualidade: qual escola para o século XXI? Uma pesquisa com vários atores no estado de São Paulo" - aprovada pelo Conselho Nacional de Desenvolvimento Científico e Tecnológico (CNPq) em 2017 (Chamada no 22/2016 - Pesquisa Inovação em Ciências Humanas, Sociais e Sociais Aplicadas) e desenvolvida pelo grupo de pesquisa Contexto Escolar, Processos Identitários da Formação de Professores e Alunos da Educação Básica (CEPId) - e tem como foco apontar a análise dos resultados obtidos no eixo Condições de Trabalho Docente, que teve como objetivo identificar a percepção que educadores da rede pública estadual paulista têm das condições de trabalho docente e de como tais condições interferem ou não na realização de seu trabalho. Participaram da pesquisa 5.005 educadores da rede supracitada, cujos dados foram coletados por meio de questionário on-line, viabilizado por uma 


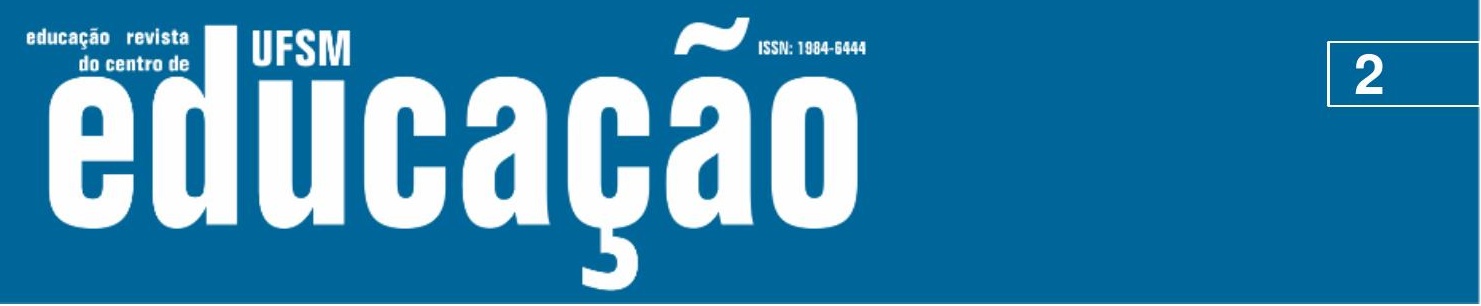

ISSN: 1984-6444 | http://dx.doi.org/10.5902/1984644447227

plataforma digital. A fundamentação teórica que pautou a análise dos dados baseouse em documentos oficiais da legislação brasileira e em estudos acerca do "trabalho docente" e das "condições de trabalho docente". Ao se confrontarem os objetivos da análise nesse eixo com os dados obtidos nos questionários, buscou-se compreender os reais desafios da escola, principalmente no que concerne às condições (materiais e imateriais) necessárias para o exercício do trabalho docente. Entende-se que, no Brasil, esse tema não tem recebido atenção suficiente por parte dos governantes, sendo fundamental a construção e a efetivação de políticas públicas que visem à melhoria das condições do trabalho docente e, consequentemente, à aprendizagem dos alunos.

Palavras-chave: Escola do século XXI; Escola pública paulista; Condições de trabalho docente; Desafios da escola na atualidade.

\section{ABSTRACT}

This article is part of a broader research named "Challenges of today's school: the journey towards the school of twenty-first century? which was performed in São Paulo's state", by the CEPId research group (an abbreviation of Scholar Context, Teacher's Identity Formation Process and Basic School Students), based on responses collected from several stakeholders related to public school environment approved in 2017 by the CNPq (National Scientific and Technological Development Council, under the code 22/2016 - Research in Innovation in Human and Social Science). This article aims to analyze the outcome of teaching working conditions work stream that intended to demonstrate the São Paulo public educators' perspective of the current working conditions at school and the way it impacts (or not) on the teachers daily work. 5,005 educators, workers of the São Paulo's public-school network, participated in the research by responding an online survey. The theoretical foundation chosen to guide the data analysis was based on official documents of Brazilian legislation and on studies about "teaching work" and "teaching work conditions". The complete understanding of the real school challenges, mainly when it concerns to the material and immaterial conditions to the teaching working necessities became possible by matching the objectives of the analysis of the "teaching working conditions work stream" with the data obtained from the online survey. It is part of the conclusions that the topic has not been priority of government's attention. Issuing new public policies is crucial to address improvements in the teaching conditions work and, therefore, to the general student's learning.

Keywords: Teaching work conditions; São Paulo public school; School of twenty-first century; School challenges today. 


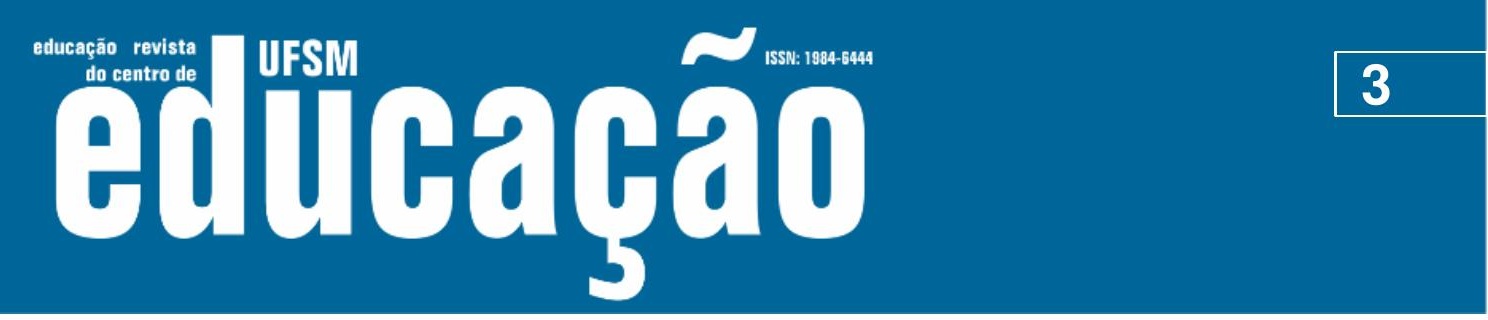

ISSN: 1984-6444 | http://dx.doi.org/10.5902/1984644447227

\section{Introdução}

Este artigo apresenta um recorte da pesquisa-mãe "Desafios da escola na atualidade: qual escola para o século XXI? Uma pesquisa com vários atores no estado de São Paulo", aprovada pelo Conselho Nacional de Desenvolvimento Científico e Tecnológico (CNPq) em 2017 (Chamada no 22/2016 - Pesquisa Inovação em Ciências Humanas, Sociais e Sociais Aplicadas) e desenvolvida pelo grupo de pesquisa Contexto Escolar, Processos Identitários da Formação de Professores e Alunos da Educação Básica (CEPId), liderado pela Profa. Dra. Vera Maria Nigro de Souza Placco, da Pontifícia Universidade Católica de São Paulo (PUC- SP), e pela Profa. Dra. Vera Lúcia Trevisan de Souza, da Pontifícia Universidade Católica de Campinas (PUC-Camp).

O objetivo da referida pesquisa foi investigar, na perspectiva de diferentes eixos de investigação", as concepções de "escola" na contemporaneidade, suas finalidades educativas, seus objetivos e atributos, apresentados por professores, gestores e outros atores ligados à escola, a fim de auxiliar na busca de mecanismos de superação aos desafios e de possibilidades para a escola pública, em meio às questões da sociedade contemporânea.

Este texto é resultado da análise realizada pelas pesquisadoras integrantes do eixo Condições de Trabalho Docente, que teve como objetivo identificar a percepção de educadores da rede pública estadual paulista acerca das condições de trabalho docente e de como tais condições interferem ou não na realização de seu trabalho.

\section{Metodologia}

A pesquisa-mãe envolveu as seguintes etapas: 1) revisão bibliográfica; 2) elaboração e aplicação de questionário on-line e 3) análise e discussão dos dados, nos diferentes eixos de investigação.

Para a realização da revisão bibliográfica, os pesquisadores do CEPId consultaram fontes digitais e impressas. Inicialmente, realizaram um levantamento da literatura sobre educação, escola e políticas públicas da educação básica brasileira, 


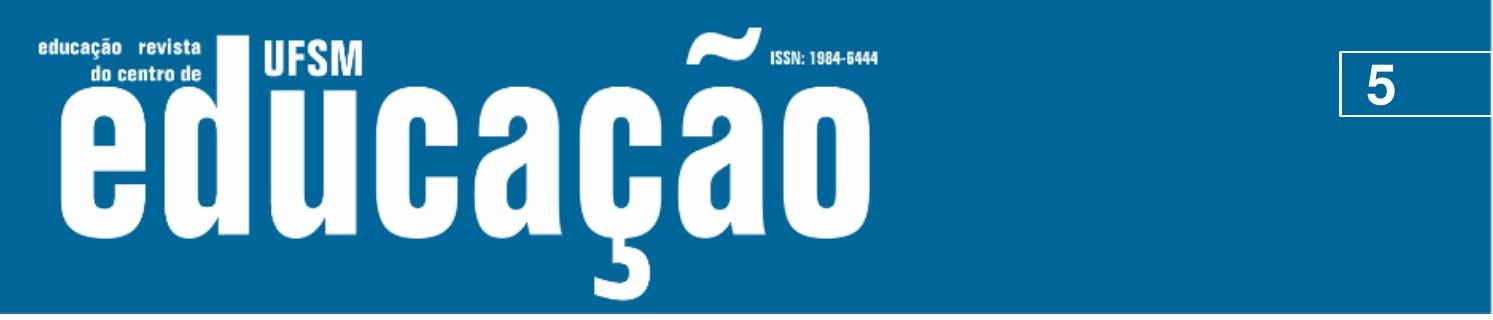

ISSN: 1984-6444 | http://dx.doi.org/10.5902/1984644447227

tais condições interferem ou não na realização de seu trabalho. Nesse sentido, buscou-se oferecer subsídios para a melhoria das condições de trabalho docente, para que elas atendam aos desafios da escola contemporânea.

Os objetivos específicos desta análise foram:

- Levantar as percepções dos educadores sobre suas reais condições de trabalho;

- Identificar as condições necessárias para que o trabalho do professor ocorra de acordo com as demandas atuais da escola e da sociedade;

- Compreender, por meio dos dados levantados, indicadores que possibilitem reflexões e avanços para uma boa qualidade da educação, o que inclui a construção e a efetivação de políticas públicas que visem à melhoria das condições de trabalho docente.

Dentre as perguntas que compuseram o questionário on-line, duas relacionavam-se diretamente com o eixo Condições de Trabalho Docente. São elas:

- Questão 37: Assinale três condições necessárias para que o trabalho do professor ocorra de acordo com as demandas atuais: Clima escolar; Equipe de trabalho; Estrutura e recursos materiais oferecidos pela escola; Formação continuada em serviço; Progressão/plano de carreira; Reconhecimento profissional; Remuneração.

- Questão 38: Agora enumere de 1 a 3, por ordem de importância (sendo 10 mais importante).

Além dessas questões específicas, outras quatro, não específicas, mas ligadas indiretamente ao referido eixo, complementaram a análise de dados. São elas:

- Questão 29: O principal desafio do professor no Brasil está relacionado a: Uso da tecnologia; Reconhecimento social; Condições de trabalho; Relação em sala de aula; Relações interpessoais para o exercício profissional; Formação continuada; Outros (campo adicional, com espaço para preenchimento).

- Questão 30: O maior desafio que você enfrenta no exercício de sua função está relacionado a: Integração família e escola; Relações interpessoais; Trabalho coletivo; Formação de professores; Motivação dos alunos; Mobilização para o 


\section{Aillbapẫ}

ISSN: 1984-6444 | http://dx.doi.org/10.5902/1984644447227

trabalho em equipe; Outros (campo adicional, com espaço para preenchimento).

- Questão 31: Assinale os três temas que você considera essenciais na formação inicial do professor na atualidade: Condições de trabalho do professor (políticas, pedagógicas, estruturais e financeiras); Conteúdo específico da disciplina (conhecimentos e práticas); Desenvolvimento humano (físico, cognitivo, afetivo e social); Diversidade (diferenças socioculturais, gênero, relações étnico-raciais e outros); Educação inclusiva (concepções e práticas específicas de ensino); Fundamentos da educação (Psicologia da Educação, História da Educação, Filosofia da Educação, Sociologia da Educação); Metodologias de ensino (concepções e práticas); Profissão docente (desenvolvimento profissional do próprio professor); Realidade educacional e escolar (do município, do estado e do país).

- Questão 32: Agora enumere de 1 a 3, por ordem de importância (sendo 10 mais importante).

Os dados obtidos no questionário on-line (questões 29, 30, 31, 32, 37 e 38) foram analisados, discutidos e organizados em dois blocos, a saber: "Condições de trabalho e as demandas atuais da escola" e "Condições de trabalho e os desafios dos profissionais da educação".

Vale explicitar que, nas questões 29 e 30, as respostas obtidas no campo aberto do item "Outros" foram analisadas segundo a frequência e a relevância para a temática. Essas respostas também foram agrupadas em diversos blocos que auxiliaram a análise dos dados.

\section{Fundamentação teórica}

Visto que as concepções de "trabalho docente" e de "condições de trabalho docente" possibilitam diferentes abordagens, neste estudo, foram adotados os conceitos propostos por Oliveira (2010) e por Oliveira e Assunção (2010), respectivamente. 


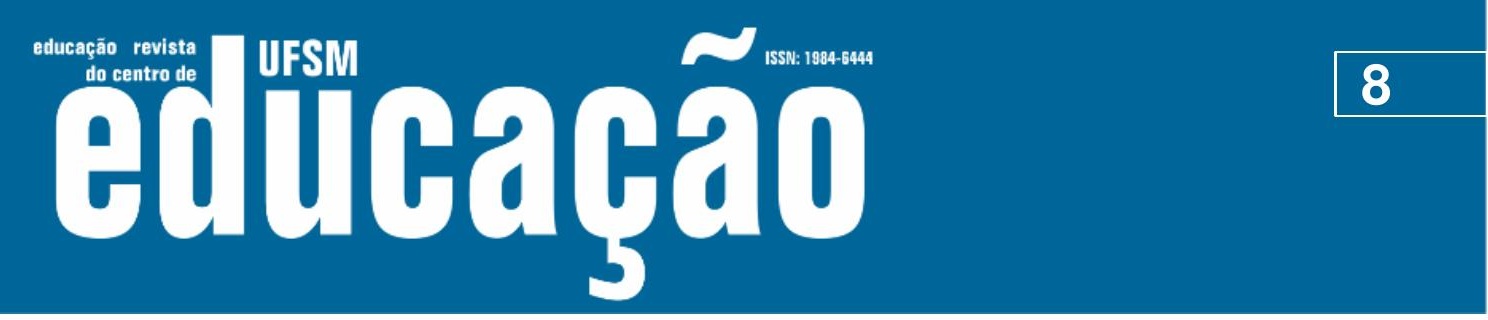

ISSN: 1984-6444 | http://dx.doi.org/10.5902/1984644447227

a ausência de políticas, torna-se necessário e urgente entender como, nos diferentes programas e projetos do governo estadual paulista, elas têm sido apropriadas e implementadas.

\section{Resultados}

Conforme explicitado, os dados obtidos no questionário on-line (questões 29, 30, 31, 32, 37 e 38) foram analisados, discutidos e organizados em dois blocos "Condições de trabalho e as demandas atuais da escola" e "Condições de trabalho e os desafios dos profissionais da educação" -, os quais serão apresentados a seguir.

\section{Condições de trabalho e as demandas atuais da escola}

Ao serem convidados a assinalar, na questão 37, três condições necessárias para que o trabalho do professor ocorra de acordo com as demandas atuais, os resultados foram os seguintes: "estrutura e recursos materiais oferecidos pela escola" (55,5\%), "remuneração" (54,1\%), “progressão/plano de carreira" (49,6\%), "reconhecimento profissional" (46,8\%), "formação continuada em serviço" (35,6\%), "equipe de trabalho" (35,3\%) e "clima escolar" $(20,4 \%)^{4}$.

Na questão 38, solicitou-se aos participantes que enumerassem as alternativas escolhidas na questão 37, de 1 a 3, segundo o grau de importância do item (sendo 1 o mais importante). Os resultados foram os seguintes: em primeiro lugar do valor "1", está a "remuneração" como mais importante condição de trabalho (28\%); em primeiro lugar do valor "2", estão "a estrutura e os recursos materiais" oferecidos pela escola $(22,8 \%)$ e em primeiro lugar do valor "3", está o "reconhecimento profissional" (19,8\%).

Esses dados vão ao encontro do que aponta Leithwood (2006 apud PEREIRA JÚNIOR, 2016, p. 19-20) quando o autor afirma que "os efeitos dos salários sobre a satisfação e a retenção dos professores não são independentes das condições de trabalho; salários elevados juntamente com más condições de trabalho podem fazer pouco para promover a retenção" do professor, em seu trabalho.

As alternativas que se referem a itens objetivos e concretos, como "estrutura material e recursos", seguido por "remuneração" e "progressão na carreira", aparecem 


\section{T-1 uss

ISSN: 1984-6444 | http://dx.doi.org/10.5902/1984644447227

docente, sem, no entanto, deixar de lado as condições de trabalho e de empregabilidade dos professores.

Gatti, Barreto e André (2011) apontam que é no cotidiano da escola, por meio de seus educadores, que se consolidam as demandas atuais da sociedade, a partir da criação e da distribuição de conhecimentos de boa qualidade e da promoção da equidade. Nesse sentido, o lugar que a docência ocupa deve ser condizente com a complexidade de sua responsabilidade na formação das novas gerações e no atendimento das demandas atuais da sociedade.

\section{Condições de trabalho e os desafios dos profissionais da educação}

As perguntas 29 e 30 intencionaram levantar os desafios enfrentados pelo professor e pelos demais profissionais que atuam na escola, respectivamente.

Dentre as alternativas de respostas apresentadas na questão 29, a alternativa "condições de trabalho" obteve o índice de resposta de 53,8\%.

Considera-se importante dirigir um olhar para os registros feitos no campo aberto "Outros", embora tenha ocorrido um percentual pequeno de respostas relacionadas à totalidade dos sujeitos $(3,02 \%)$, as quais foram organizadas em categorias pós-definidas, considerando-se a semelhança/proximidade das falas, e agrupadas da seguinte maneira:

- Alunos

- Aspectos relacionais

- Condições de trabalho

- Ensino-aprendizagem

- Estrutura física

- Família

- Formação

- Remuneração

- Tecnologia

- Valorização e reconhecimento social da profissão

- Violência 


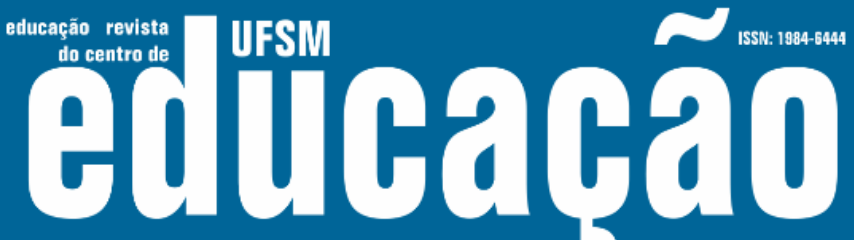

ISSN: 1984-6444 | http://dx.doi.org/10.5902/1984644447227

Feita uma breve análise, pode-se constatar a grande variedade de temáticas trazidas pelos participantes, muitas das quais constituem-se objeto de análise dos demais eixos da pesquisa e, por isso, estão direcionadas a eles. No entanto, é importante destacar algumas falas pertinentes ao eixo Condições de Trabalho Docente, para exemplificar o entendimento dos professores quanto a esse tema: mesmo tendo na questão a possibilidade de assinalar a alternativa "condições de trabalho", esse item é reafirmado, com incidência significativa de respostas, na direção de clamarem por melhores condições de trabalho, o que certamente os tornaria "melhores professores".

Com relação à "remuneração", são comuns alegações à baixa, defasada e insatisfatória remuneração recebida pelos professores, tornando difícil seu sustento e obrigando-os a exercerem outro trabalho, em um período que, na opinião deles, precisaria ser dedicado aos estudos e ao aperfeiçoamento. A ausência de equiparação salarial com os demais profissionais com formação universitária também é apontada como fator que torna a profissão pouca atrativa e desvalorizada.

Foram também relevantes as falas que denotam a pouca valorização e o reconhecimento social da profissão, sendo que, nem sempre, isso se deve apenas à baixa remuneração, mas, sobretudo, à pouca valorização e ao descaso "tanto por parte da sociedade, como do poder público em relação aos professores", como aponta um dos sujeitos.

São comuns os sentimentos de desrespeito que vivenciam, tanto em relação a eles, como à educação, explicitados na seguinte fala: "a maioria dos professores tem vergonha de dizer que são professores".

Os aspectos estruturais foram mencionados, mas com pouca incidência, e entendidos como falta de material e/ou material de pouca qualidade, salas superlotadas, escolas "sujas e imundas", dentre outros.

Na questão 30, não havia explicitamente o item "condições de trabalho", mas alternativas que poderiam remeter a ele, tal como conceituado e entendido neste eixo, e que foram assinaladas pelos sujeitos. São elas: "relações interpessoais", "trabalho coletivo" e "mobilização para o trabalho em equipe", que julgamos importante 


\section{Fism Autbahat

ISSN: 1984-6444 | http://dx.doi.org/10.5902/1984644447227

profissionais da educação, por meio de estatutos, ingresso e progressão na carreira via concurso público e titulação, aperfeiçoamento profissional continuado e "condições adequadas de trabalho" (item VI).

Ao analisar o Plano Nacional de Educação (PNE) (BRASIL, 2014), em vigência para o período 2014-2023, o autor pontua, dentre outras diretrizes, duas diretamente ligadas aos docentes, coincidentes com os princípios da CF - a promoção do princípio de gestão democrática (VI) e a valorização dos profissionais da educação (IX) -, diretrizes e princípios ligados às condições de trabalho do professor.

Ainda ao analisar o PNE, Pereira Júnior (2016) aponta que, no Sistema Nacional de Avaliação da Educação Básica (Saeb), há uma abordagem mais abrangente das condições de trabalho docente, que deve compreender, dentre seus indicadores de avaliação institucional: o perfil do alunado e dos profissionais; as relações entre o corpo docente, o corpo técnico e o corpo discente; a infraestrutura das escolas; os recursos pedagógicos disponíveis e os processos da gestão, entre outros indicadores relevantes (item II) (BRASIL, 2014, art. 11).

A meta 20.7 do PNE aborda o financiamento da educação, indicando critérios para o financiamento da educação básica, e destaca a implementação do Custo Aluno Qualidade (CAQi) como um dos parâmetros a serem considerados:

[...] o cálculo de gastos educacionais com investimentos em qualificação e remuneração do pessoal docente e dos demais profissionais da educação pública, em aquisição, manutenção, construção e conservação de instalações e equipamentos necessários ao ensino e alimentação e transporte escolar (BRASIL, 2014, s/p).

Como se pode observar, as condições de trabalho docente estão apontadas em importantes documentos orientadores das políticas públicas em educação, tanto no que diz respeito aos recursos materiais, como às relações concernentes ao processo de trabalho - com ênfase na gestão democrática e nas condições do emprego -, aos planos de carreira e ao piso salarial, para o pleno exercício da profissão.

Considerando-se que tais documentos inspiram a implementação das políticas públicas estaduais e municipais, tem-se, em cada instância do sistema, os respectivos 


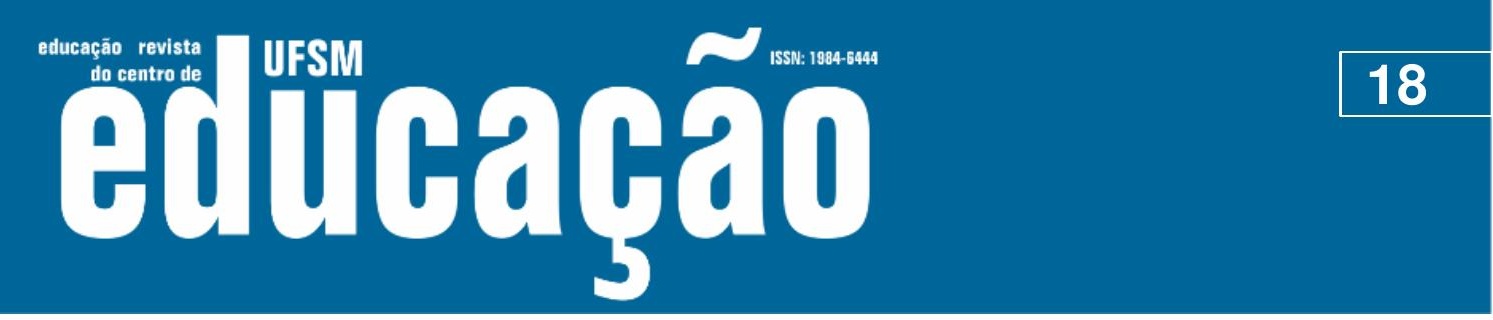

ISSN: 1984-6444 | http://dx.doi.org/10.5902/1984644447227

BERTAGNA, Regiane Helena; MELLO, Liliane Ribeiro de. Avaliação institucional participativa: o olhar a partir da realidade de uma escola estadual em São Paulo Brasil. Educação em Debate, Fortaleza, anos 35-38, n. 66-71, jul./dez. 2013; jan./dez. 2014; jan./dez. 2015; jan./jun. 2016. Disponível em: http://www.periodicosfaced.ufc.br/index.php/educacaoemdebate/article/view/76/39. Acesso em: 29 jan. 2020.

BRASIL. Presidência da República. Constituição Federal da República Federativa do Brasil. Brasília, 1988.

BRASIL. Presidência da República. Lei no 9.394/1996, de 20 de dezembro de 1996. Estabelece as Diretrizes e Bases da Educação Nacional. Brasília, 1996.

BRASIL. Presidência da República. Lei no 13.005/2014, de 25 de junho de 2014. Aprova o Plano Nacional de Educação (PNE) e dá outras providências. Brasília, 2014.

CARLOTTO, Mary Sandra. A síndrome de Burnout e o trabalho docente. Psicologia em Estudo, Maringá, v. 7, n. 1, p. 21-29, jan./jun. 2002. Disponível em: https://www.scielo.br/pdf/pe/v7n1/v7n1a03.pdf. Acesso em: 11 jun. 2020.

ESTEVE, José Manuel. Mudanças sociais e função docente. In: NÓVOA, António (Org.). Profissão professor. 2. ed. Porto: Porto Editora, 1995.

FÉLIX, Jeane. Entrevistas on-line ou algumas pistas de como utilizar bate-papos virtuais em pesquisas na educação e na saúde. In: MEYER, Dagmar E.; PARAÍSO, Marlucy A. (Orgs.). Metodologias de pesquisas pós-críticas em educação. Belo Horizonte: Mazza Edições, 2012.

GATTI, Bernadete Angelina; BARRETO, Elba Siqueira de Sá. Professores do Brasil: impasses e desafios. Brasília: UNESCO, 2009.

GATTI, Bernadete Angelina; BARRETO, Elba Siqueira de Sá; ANDRÉ, Marli Eliza Dalmazo Afonso de. Políticas docentes no Brasil: um estado da arte. Brasília: UNESCO, 2011.

HÖFLING, Eloisa de Mattos. Estado e políticas (públicas) sociais. Cadernos Cedes, ano XXI, n. 55, p. 30-41, nov./2001. Disponível em: https://www.scielo.br/pdf/ccedes/v21n55/5539.pdf. Acesso em: 02 maio 2020.

OLIVEIRA, Dalila Andrade. Trabalho docente. In: OLIVEIRA, D. A.; DUARTE, A. M. C.; VIEIRA, L. M. F. DICIONÁRIO: trabalho, profissão e condição docente. Belo Horizonte: UFMG/Faculdade de Educação, 2010. CDROM. 


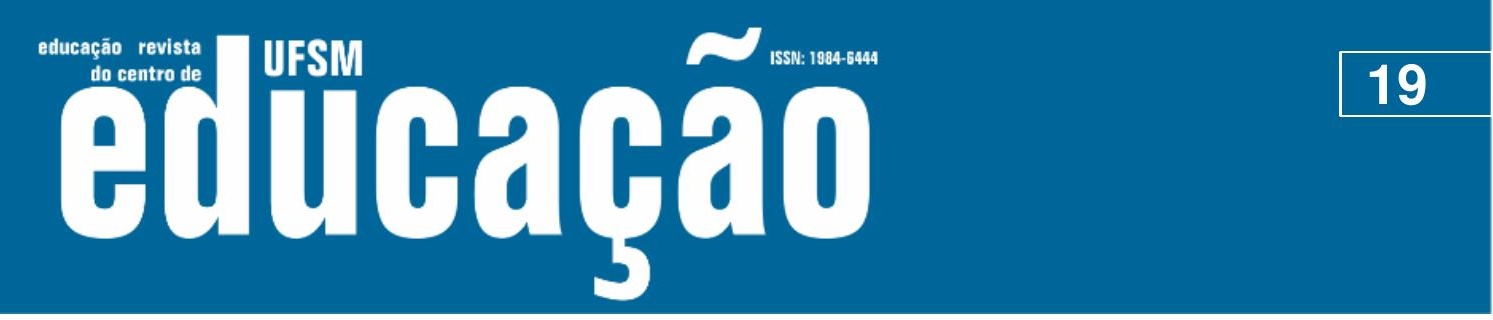

ISSN: 1984-6444 | http://dx.doi.org/10.5902/1984644447227

OLIVEIRA, Dalila Andrade.; ASSUNÇÃO, Ada Ávila. Condições de trabalho docente. In: OLIVEIRA, D. A.; DUARTE, A. M. C.; VIEIRA, L. M. F. DICIONÁRIO: trabalho, profissão e condição docente. Belo Horizonte: UFMG/Faculdade de Educação, 2010. CDROM.

PEREIRA JÚNIOR, Edmilson Antonio. Condições de trabalho docente nas escolas de educação básica no Brasil: uma análise quantitativa. 2016. Tese (Doutorado) Universidade Federal de Minas Gerais, Faculdade de Educação. Belo Horizonte, 2016.

http://www.bibliotecadigital.ufmg.br/dspace/bitstream/handle/1843/BUOS-

em:

AQQPSG/tese_final_edmilson.pdf?sequence=1f. Acesso em: 29 jan. 2020.

REIS, Adriana Teixeira. Análise dos contextos de uma política de iniciação à docência: Projeto Bolsa Alfabetização da Secretaria de Educação do Estado de São Paulo. 2018. Tese (Doutorado em Educação: Psicologia da Educação) - Pontifícia Universidade Católica de São Paulo, São Paulo, 2018.

SÃO PAULO. Assembleia Legislativa do Estado de São Paulo. Lei no 16.279, de 09 de julho de 2016. Aprova o Plano Estadual de Educação de S. Paulo e dá outras providências. Disponível em: https://www.al.sp.gov.br/repositorio/legislacao/lei/2016/lei-16279-08.07.2016.html.

Acesso em: 04 maio 2020.

TARDIF, Maurice; LESSARD, Claude. O trabalho docente: elementos para uma teoria da docência como profissão de interações humanas. 9. ed. Petrópolis, RJ: Vozes, 2014.

\section{(c) $)$ (i) (2)}

This work is licensed under a Creative Commons Attribution-NonCommercial 4.0 International (CC BY-NC 4.0)

\section{Notas}

\footnotetext{
1 Os eixos da pesquisa são: (1) Condições de Trabalho Docente; (2) Finalidades Educativas Escolares; (3) Formação Inicial e Continuada de Professores; (4) Tecnologias; (5) Políticas Públicas e (6) Vulnerabilidades.

2 Função exercida por docentes, nas unidades escolares. Fonte: Resolução SE no 75, de 30/12/2014. Disponível em: http://siau.edunet.sp.gov.br/ltemLise/arquivos/75_14.HTM?Time=09/06/2020\%2010:56:51. Acesso em: 09 jun. 2020.

3 Função exercida por docentes, nas Diretorias de Ensino. Fonte: Resolução SE no 75, de 30/12/2014. Disponível em: http://siau.edunet.sp.gov.br/ltemLise/arquivos/75_14.HTM?Time=09/06/2020\%2010:56:51. Acesso em: 09 jun. 2020.
} 


\section{uss Eltibahá}

ISSN: 1984-6444 | http://dx.doi.org/10.5902/1984644447227

${ }^{4}$ Cabe explicar que esses e outros dados que serão apresentados, na somatória, totalizam um percentual acima de $100 \%$, pelo fato de os sujeitos terem assinalado três alternativas da questão. Portanto, considerou-se o total de respostas, e não de sujeitos.

5 Segundo Maslach, Schaufeli e Leiter (2001 apud CARLOTTO, 2002), Síndrome de Burnout é um tipo de estresse ocupacional que acomete profissionais envolvidos com qualquer tipo de cuidado em uma relação de atenção direta, contínua e altamente emocional. As profissões mais vulneráveis são geralmente as que envolvem serviços, tratamento ou educação. Atualmente, a definição mais aceita do Burnout é a fundamentada na perspectiva social-psicológica de Maslach e colaboradores, sendo esta constituída de três dimensões: exaustão emocional, despersonalização e baixa realização pessoal no trabalho. 